\title{
Research on Higher Education Teaching Model Based on OBE
}

\author{
Xinhao Wang \\ School of management science and engineering \\ Shandong Technology and Business University \\ Yantai, China \\ xinhaowang@126.com
}

\author{
Luqiao Ning \\ School of management science and engineering \\ Shandong Technology and Business University \\ Yantai, China \\ ningluqiao@126.com
}

\begin{abstract}
This paper aims to solve the difficult problem of how to convert the "student-centered" teaching model in the current reform of higher education in China. In this paper, the OBE concept, which is very popular in higher education both at home and abroad currently, is applied to practice. On the basis of the clarification of the OBE concept, an OBTL model suitable for the current situation of China's higher education reform is established and the basic characteristics of this model is identified. This paper summarizes the connotation and implementation steps of the OBTL model through literature research method, and compares and analyzes the difference between the OBTL model and the traditional teaching model. The results we obtained show that this OBTL model will contribute to the acceleration of the reform of the higher education teaching model and the improvement of the teaching quality in universities in China, and it also puts forward some new demands on Chinese universities and teachers.
\end{abstract}

\section{Keywords-OBE; OBTL; Higher education; Teaching model}

\section{OUTCOME-BASED EDUCATION}

Outcome-based Education (OBE) originated from the United States in the 1980s, derived from the theory of educational objectives, competency based education, learning for mastery and Standardized Evaluation. Spady W.D is the American scholar who pioneered the concept of OBE in his book Outcome-Based Education: Critical Issues and Answers. He proposed two keys of the outcome-based education system: developing a clear set of learning outcomes that can be focused and establishing the conditions and opportunities that enable and encourage all students to achieve those essential outcomes [1].

With the popularity of OBE in the American education, it spread too many countries and regions, such as Australia, the United Kingdom, Japan, South Africa and Hong Kong of China in the 1990s.According to OBE concept, the education process should be based on the realization of students' specific learning outcomes [2]. This means that the educator should design and implement appropriate education system around the knowledge and ultimate performance abilities to the highest possible levels before students leave school, so as to ensure the intended learning outcomes. "Learning outcome driven" of OBE is in sharp contrast to the traditional "teaching content driven".
With the idea of "Success for All" [3], the OBE pyramid consists of five elements: paradigm of operating, two key purposes, three key premises, four operating principles and five generic domains of practice [1]. The operating paradigm, which is on the top level of pyramid structure, set up a viewpoint that the education should operate a shift which makes "accomplishing results" more important than "providing services". Other levels of OBE pyramid are decomposed step by step to implement the viewpoint and ensure the patterns of concrete action.

In 1989, the Washington Accord was sponsored by six countries including the United States, the United Kingdom, Canada, Australia, Ireland and New Zealand. Washington Accord focuses on the certification of international engineering education, and marks the transformation from concept to practice of OBE education concept. China officially became a member of the Washington Accord in June 2016, which means that the OBE education concept will surely play a demonstration role in the reform and practice of our higher education.

\section{OUTCOMES-BASED TEACHING AND LEARNING MODEL}

With the popularity of the OBE concept, a series of certification standards in European and American countries, represented by EC2000 (engineering curriculum plans and certification standards issued and implemented by Accreditation Board of Engineering and Technology in 1995), have attached great importance to "learning outcome" and introduced into themselves. And then, "learning outcome" became one of important quality criterions for these countries' national degree standards, higher education objectives and professional training programs.

The exploration of OBE concept to practice started from the reform of teaching model of higher education in medical field in European and American countries. The United Kingdom has set up a special Outcome-Based Education Center and the Learning Outcomes and their Assessment Project, which requires each university to define and assess learning outcomes in order to ensure the quality of higher education [4].

And the subsequent Outcomes-Based Teaching and Learning (OBTL) model, including "intended learning outcomes - teaching activities - outcome-based assessment", 
emphasizes the development of teaching activities to support and guarantee the learning outcomes [5]. This teaching model breaks through the limitations of traditional teaching models such as problem-based teaching model and project-based teaching model. Instead of traditional content-oriented and knowledge-oriented designing and teaching, OBTL model is oriented by students' intended abilities, and adopt the reverse design method to implement and assessment teaching process, so as to improve continuously. So far, OBTL has been popularized in many countries and regions. Professional committees, higher education departments and many universities in Canada, Australia, Japan, Hong Kong and Taiwan of China have adopted the OBTL model to improve the teaching and learning effects [6].

As the largest country in Higher Education in the world and also a member of the Washington Accord, China started late in the introduction of OBE concept and OBTL model practice in the field of higher education, and is now entering a period of extensive attention and active exploration. Shantou University is the pioneer of making use of CDIO engineering education model for OBE engineering education reform. And it has successfully explored the higher education teaching model based on the concept of OBE, including four key steps: setting up the professional level of intended learning outcomes, establishing the matching matrix of curriculum and training standards, determining the curriculum level of intended learning outcomes and the corresponding teaching strategy, assessing the actual learning outcomes [7].

Based on the achievements of OBE researchers and OBTL practitioners at home and abroad, the author proposes the teaching model of higher education based on OBE model. This model for higher education starts from the talent demand, which comes from both the national and social needs and the industry standards. Combined with the university orientation, the demand will define the graduation ability requirements for college students. The requirements should be divided into three levels: school level, professional level and course level. According to the order of the hierarchy, the corresponding requirements gradually become concrete from abstraction. Then, we should focus on the intended learning outcomes, which are matched to the graduation ability requirements. The learning outcomes include three aspects: knowledge outcomes, technical outcomes, and ability outcomes. Curriculum structure should be adapted for the defined learning outcomes. Reset the training objectives, rebuild the teaching framework, and set up the outcome assessment are three important activities in this process. Note that the OBTL model is a closed-loop structure, so the feedback and continuous improvement is essential. The OBTL model for higher education is shown in Fig.1.

\section{CHARACTERISTICS OF OBTL MODEL}

OBTL emphasizes "learning outcomes" and the according reverse design, which breaks the positive design process of the traditional "knowledge-oriented" teaching model, and truly realizes the "student-centered" teaching model. The determination of "learning outcomes" and the design of corresponding training objectives, teaching framework and evaluation system, in addition to considering the school orientation, also need to refer to the national and industry standards. Multiple roles including Industry, employers, alumni and other representatives of social needs should also be involved in this process.

Generally speaking, OBTL model has the following characteristics:

\section{1) Focus on defining the ability and level of graduates}

Many international professional certification systems established in accordance with the concept of OBE have clearly defined the knowledge, ability and professional qualities that students should possess. The application of OBTL mode in higher education requires setting a series of evaluable learning outcomes, each of which represents the technical level and potential ability of the graduate in the corresponding major.

In the traditional teaching system, the teaching objectives mainly consider how well the students master the subject knowledge. Incorporating some professional certification standards into higher education as the graduation requirements of students, the teaching objectives can be clearly focused on the most meaningful learning outcomes for students' future, and the cultivation of students' practical level and comprehensive ability can be strengthened.

\section{2) Reverse design and reconstruct the teaching system}

In the traditional teaching system, teaching activities are carried out step by step: the teaching content is determined first, then the curriculum plan and learning plan are made according to the teaching content (subject knowledge), and the teaching process is completed in a step-by-step manner, in order to achieve the teaching objective of mastering the subject knowledge. The OBTL model emphasizes that "output determines input", which requires the setting of teaching objectives to be earlier than the determination of teaching content, and then the order of curriculum planning, learning plan and teaching process remain unchanged. The OBTL model will flexibly select the subject knowledge according to the defined intended learning outcomes; clarify the effect of each course on the intended learning outcomes; form the matching matrix between the selected courses and the intended learning outcomes; and then make the learning plan and design the teaching process on this basis. The OBTL model breaks the inherent order of the traditional teaching model and brings unprecedented teaching effects through the reverse design of some steps. 


\section{3) Student-centered teaching}

Although the traditional teaching model with teaching resources and teaching content as the core is keep striving to change, it is still difficult to get rid of the stereotype that teachers are the dominant and students are passive to accept knowledge. The OBTL model focuses on the learning outcomes of students, whose teaching objectives and teaching methods are no longer designed around how to teach, but rather focus more on what students should learn and how they should learn. In line with the transformation of the teaching model, the teaching role played by teachers should also be gradually transformed from "actors" who teach the knowledge in front of the stage to "directors" who guide the practice behind the scenes. Students' understanding and perception of "learning outcomes" also helps to improve their enthusiasm for independent learning. Instead of passively waiting to accept knowledge, they will actively explore knowledge, practice skills, and even innovate to meet their own (internal) requirements and social (external) requirements for their ability.

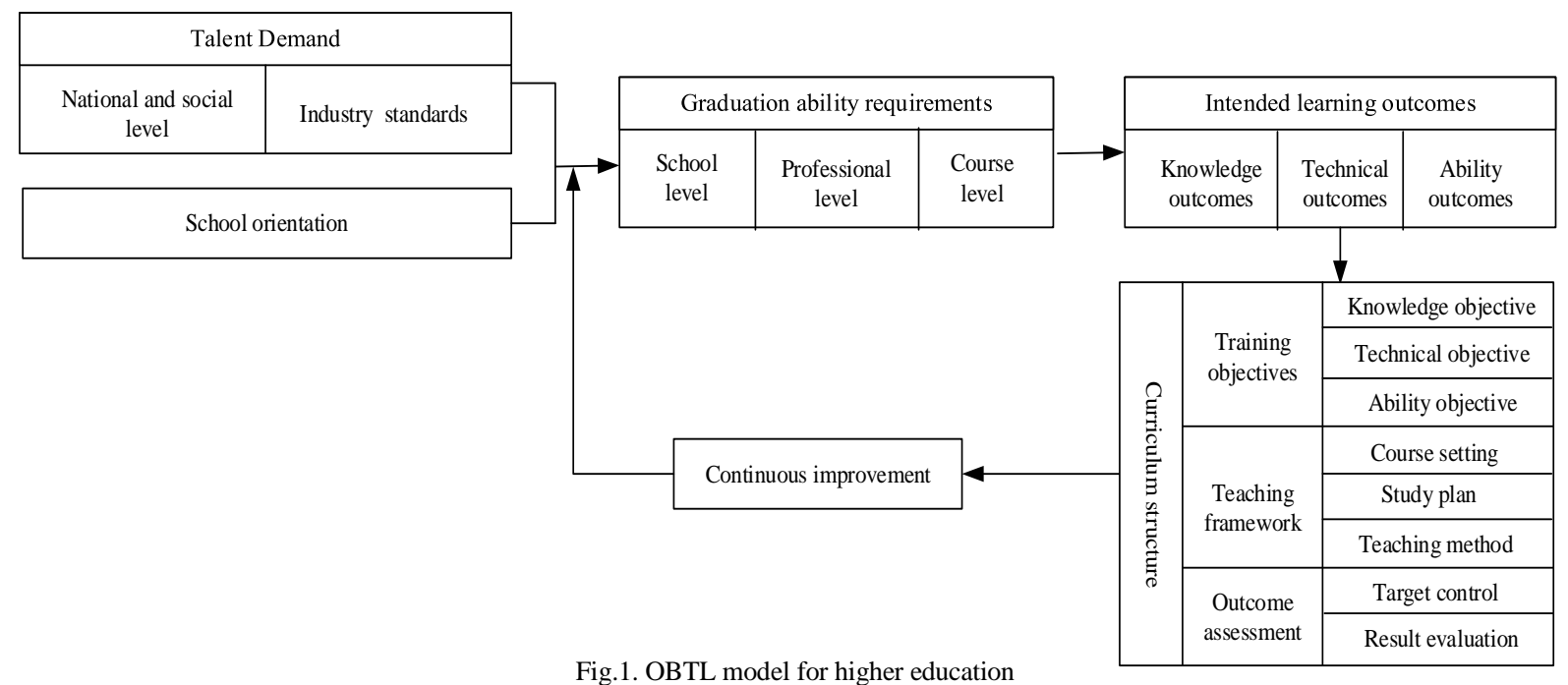

4) Emphasize assessment and feedback on learning outcomes

The OBTL model is a cyclical education reform model, and this closed-loop structure is realized by the learning outcomes evaluation system and the continuous improvement of the definition of learning outcomes. The OBE model, proposed by Chandrama Acharya, consists of four main steps: (1) defining the learning outcomes, (2) Realizing the learning outcomes, (3) Assessing the learning outcomes, and (4) Using learning outcomes [8]. Among them, the two steps of assessing the learning outcomes and using the learning outcomes are indispensable and particularly complex.

Many countries in Europe and the United States have established national institute for learning outcomes assessment to promote the exchange and sharing of assessment experiences between different universities and colleges. The traditional teaching model often uses the unified test to evaluate the teaching process, while the OBTL model needs to set up a more complex multiple evaluation system to assess the "ability indicators" that are difficult to be explicitly and quantified.

TABLE I THE DIFFERENCE BETWEEN OBTL AND TRADITIONAL TEACHING MODEL

\begin{tabular}{|c|c|c|}
\hline \multirow{2}{*}{ Contrast content } & \multicolumn{2}{|c|}{ Teaching model } \\
\hline & OBTL model & traditional model \\
\hline teaching objectives & Cultivate comprehensive ability & Master the subject knowledge \\
\hline Teaching content & $\begin{array}{l}\text { Personalized } \\
\text { flexible choice }\end{array}$ & $\begin{array}{l}\text { standardization } \\
\text { Fixed system }\end{array}$ \\
\hline Teaching process & $\begin{array}{c}\text { Student-centered } \\
\text { students actively explore }\end{array}$ & $\begin{array}{c}\text { Teacher-centered } \\
\text { students passively accept }\end{array}$ \\
\hline Teaching evaluation & $\begin{array}{l}\text { Multiple evaluation } \\
\text { continuous improvement }\end{array}$ & Single assessment \\
\hline
\end{tabular}

Table I The characteristics of the new OBTL model and the main differences from the traditional teaching model of higher education. 


\section{THE SIGNIFICANCE OF OBTL MODEL FOR HIGHER EDUCATION}

Introducing the OBTL teaching model into the field of higher education is not a complement to traditional teaching model such as problems-based and projects-based teaching model, but a reform and innovation of the current teaching model based on the definite OBE concept. In recent years, with the popularization and application of educational concepts such as MOOC, SPOC and Flipped Classroom, higher education in our country has also been committed to the realization of the "student-centered" teaching model reform. The emergence of the OBTL teaching model will not only help to speed up the reform process, but also have important practical significance for improving the talent training model of higher education.

\section{A. More clear higher education training objectives}

The training goal of the OBTL teaching model is no longer simply "school-oriented" or "teacher-oriented", but to take the talent demands of the society into full consideration, and to be determined by analyzing the vocational ability requirements of the industry and enterprises. In this way, it is possible to subdivide the more abstract traditional training objectives, set up multi-level objective needs, and guide each student to achieve their own personalized goals, so as to pursue selfgrowth and realization in the future.

\section{B. More scientific higher education curriculum structure}

According to the idea of reverse design in the OBTL teaching model, the curriculum structure determined by "learning outcomes" will be just matched with the vocational ability required by the graduates. It can truly realize the integration and connection between different units of one single course and different courses of the course group, and promote the organic integration of theoretical knowledge teaching and practical skills training.

\section{Guaranteed higher education quality}

The "learning outcomes" emphasized by the OBTL teaching model includes not only knowledge-based learning outcomes and experimental skill-based learning outcomes in higher education institutions, but also ability-based learning outcomes that meet the professional certification standards of relevant industries. Graduates trained in the OBTL teaching model are more suitable for the requirements of future recruitment enterprises and are easy to be recognized by the society. Their feedback and suggestions will ensure continuous improvement of the personnel training quality of higher education.

\section{CONCLUSIONS}

The introduction of OBTL teaching model, which is based on OBE concept, in the field of higher education of our country is conducive to promoting the process of higher education teaching reform in China. However, the implementation of the OBTL teaching model has put forward high requirements for both universities and teachers. The OBTL teaching model requires teachers to invest a lot of time and energy to rebuild the teaching framework. The phenomenon of "emphasizing scientific research rather than teaching" in Chinese universities is not conducive to motivating teachers to participate in the teaching reform, and thus cannot guarantee the continuous development and improvement of OBTL teaching model [7].

It is necessary for universities and colleges in our country to participate in the construction process of international certification standards, and gradually carry out mutual recognition of credits, courses and majors between domestic and foreign universities and colleges, so as to realize the internationalization of higher education in China.

\section{REFERENCES}

[1] Spady, W. D, Outcome-Based Education: Critical Issues And Answers. Arlington, VA: American Association of school Administrators. 1994.

[2] Willis S, Kissane B, Outcome-Based Education: A Review of the Literature. Education Department of Western Australia. Oct 1995.

[3] Spady, W. G, Marshall K. J, Beyond Traditional Outcome-based Education, Educational Leadership, vol. 2, pp. 66-75, 1991.

[4] C. Maggie, D. Christopher; H. Linda and R. Catherine, Learning outcomes and their assessment: putting Open University pedagogical practice under the microscope, in $1^{\text {st }}$ International Conference on Enhancing Teaching and Learning through Assessment, Hong Kong, China, July 2005.

[5] Gladie L, Connie S, Outcome-Based Education and Student Learning in Magenerial Accounting in Hong Kong, Journal of Case Studies in Accreditation and Assessment, pp. 4-10, 2012.

[6] Mong Y, Mangtang C, Francis Kar. H. C, Web-Based Outcome-Based Teaching and Learning - An Experience Report, Lecture Notes in Computer Science, pp. 475-483, 2008.

[7] Gu Peihua, Hu Wenlong, Lin Peng, Bao Nengsheng, Lu Xiaohua et al. OBE Engineering Education Model in Shantou University, Research in Higher Education of Engineering, vol. 1, 2014.

[8] Chandrama Acharya, Outcome-Based Education (OBE): A New Paradigm for Learning, CDTLink, vol. 7, No. 3, 2003. 